\title{
Tomada de Decisão no Sharing Game: Um Estudo Exploratório sobre o Efeito de Variáveis Contextuais
}

\author{
Fanny Silveira e Silva ${ }^{1}$ \\ Programa de Pós Graduação em Psicologia da Universidade Federal de São Carlos, \\ São Carlos, SP, Brasil \\ Diogo Conque Seco Ferreira \\ Departamento de Psicologia da Universidade Federal de Sergipe, São Cristóvão, SE, Brasil
}

\section{Resumo}

O Sharing Game é um jogo econômico que estuda as motivações envolvidas na distribuição de recursos. O participante deve escolher, em uma série de tentativas, entre duas opções com uma quantidade de recursos para ele e para outro participante passivo. Nestas opções, a diferença entre os recursos dos participantes é sempre a mesma, mas em uma delas - opção ótima - o distribuidor recebe mais e o outro participante mais ainda, e em outra - opção não ótima - o distribuidor recebe menos e o outro menos ainda. A partir das escolhas dos participantes, é averiguado quantos foram otimizadores, igualitários e competitivos. O objetivo deste trabalho foi investigar o Sharing Game em diversos contextos. Foram realizadas sete condições $(n=233)$ com estudantes universitários recrutados por conveniência. As condições envolveram ganho e perda de recurso, dinheiro hipotético e real, distribuição de tempo e informação prévia sobre o receptor. A porcentagem de escolhas ótimas em cada condição foi calculada e os participantes foram classificados em uma das três categorias apresentadas. Em todas as condições, a maioria das escolhas do distribuidor balanceou seus recursos com os do receptor. Nas condições em que o receptor já começava o jogo com pontos, houve uma maior frequência de escolhas competitivas. A frequência de escolhas ótimas foi maior na condição Ganho de Dinheiro Real, As escolhas igualitárias foram mais frequentes na condição Tempo para realizar uma Tarefa Tediosa. Variações na distrbuição das escolhas demonstram que o Sharing Game é sensível à situação em que é jogado.

Palavras-chave: Comportamento de escolha, tomada de decisão, Sharing Game, variáveis contextuais.

\section{Decision Making in the Sharing Game: An Exploratory Study on the Effect of Contextual Variables}

\begin{abstract}
The Sharing Game, an economic game, studies the motivations involved in resources allocation. The participant faces several trials in which he must choose between two options, both with an amount of resources for him and for other passive participant. On these two options, the difference between the participants' resources is always the same, but in one of them - optimal option - the distributor receives more and the receiver even more, and in another - non optimal option - the distributor receives less and the other even less. From their choice, participants may be classified as optimizers, egalitarians or competitives. The objective of this study was to provide different contexts for the Sharing Game
\end{abstract}

1 Endereço para correspondência: Departamento de Psicologia, Avenida Marechal Rondon, S/n - Jardim Rosa Elze, São Cristóvão - SE, 49100-000. E-mail: fanny_silveira@hotmail.com e diogoseco@gmail.com 
and investigate their effects. Seven conditions $(n=233)$ were conducted with university students recruited by convenience. Conditions involved gain and loss of resource, real and hypothetical money, distribution of time and prior information about the receiver. The percentage of optimal choices in each condition was calculated and the participants were classified into one of those three categories accordingly. In all conditions, most choices of the distributor balanced their resources with the receiver. In conditions where the receiver has already started the game with points, there was a higher frequency of competitive choices. The frequency of optimal choices was higher in the condition Sharing Real Money. The egalitarian choices were more frequent in the condition Sharing Time to perform a Tedious Task. Variations in the choices distribution demonstrate that the Sharing Game is sensitive to the situation in which it is played.

Keywords: Decision making, Sharing Game, economic game, contextual variables.

\section{Toma de Decisiones en el Sharing Game: Un Estudio Exploratorio sobre el Efecto de Variables Contextuales}

\section{Resumen}

El Sharing Game es un juego económico que estudia las motivaciones que intervienen en la distribución de los recursos. El participante debe elegir, en una serie de intentos, entre dos opciones que ofrecen recursos para él y otro participante pasivo. La diferencia entre los recursos de los participantes es siempre la misma, pero en uno de ellas - opción optimizada - el distribuidor recibe más y otro participante más aún, y en la otra - opción no optimizada - el distribuidor recibe menos y el otro menos. Desde de sus elecciones, se averigua cuántos eran los optimizadores, igualitarias y competitivos. Este estudio investigó el Sharing Game en diferentes contextos. Fueran realizadas siete condiciones con estudiantes universitarios $(n=233)$. Las condiciones implican la ganancia y la pérdida de recursos, el dinero hipotético y real, la distribución del tiempo y de la información previa sobre el receptor. Se calculó el porcentaje de decisiones óptimas en cada condición y los participantes fueron clasificados en una de tres categorías presentadas. En todas las condiciones, la mayoría de los dispensadores balancearón sus recursos con el receptor. En condiciones en las que el receptor estaba empezando el juego con puntos, hubo una mayor frecuencia de opciones competitivas. La frecuencia de las elecciones óptimas fué más grande en la condición que recibió Dinero Real; las opciones igualitarias fue más frecuente en la condición de tiempo dividido para realizar una tarefa tediosa. Los cambios en la distribución muestran que el Sharing Game es sensible al contexto.

Palabras clave: Toma de decisiones, Sharing Game, juego econômico, variables contextuales.

As interações sociais envolvem escolhas que impactam o bem-estar daqueles que as realizam e o dos demais. Os dilemas sociais são exemplos destas interações, nos quais "as pessoas enfrentam uma situação de motivação mista, na qual podem ser motivadas a seguir seu próprio interesse, mas também a seguir o interesse coletivo, sabendo que ambos interesses são divergentes" (van Dijk, Wit, Wilke, \& de Kwaadsteniet, 2010, p. 47). Podem-se definir dilemas sociais, então, como situações de interação social nas quais há uma divergência entre o interesse do indivíduo e o interesse do coletivo (e.g., Shelley, Page, Rives, Yeagley, \& Kuhlman, 2010; van Dijk et al., 2010; van Lange \& Joireman, 2010). Assim, o indivíduo pode optar por seguir seus próprios interesses, seguir os interesses do seu grupo, ou ainda tentar equilibrá-los quando possível.

Van Lange e Joireman (2010) desenvolveram um quadro conceitual através do qual os dilemas sociais são analisados em termos de questões sociais e temporais relevantes para os conflitos sociais (indivíduo X coletivo) e para os conflitos temporais (curto prazo $\mathrm{X}$ longo prazo) 
subjacentes aos dilemas. Neste quadro conceitual, os dilemas sociais são analisados em termos de diversas orientações sociais e temporais relevantes à tomada de decisão. As seis orientações sociais são: altruísmo, que maximiza o resultado dos outros; cooperação, que maximiza o resultado do coletivo; igualitarismo, que minimiza a diferença entre os ganhos da pessoa e dos outros; individualismo, que maximiza os ganhos da própria pessoa; competição, que maximiza a diferença entre os ganhos da pessoa e dos outros; e agressividade, que minimiza os ganhos dos outros. Segundo Eek e Gärling (2008), apesar de seis orientações poderem ser identificadas, apenas as orientações de valor social cooperativa, competitiva ou individualista são tipicamente trabalhadas na maioria dos estudos envolvendo os dilemas sociais.

De acordo com van Lange e Joireman (2010), pessoas adotam estratégias diferentes em diferentes situações. Assim, acredita-se que, em determinado contexto, uma pessoa cooperativa é uma pessoa que tem uma probabilidade maior de comportar-se cooperativamente e uma probabilidade relativamente menor de comportar-se como individualista ou competitivo. Isso ocorre porque há uma variação nas circunstâncias externas nas quais o indivíduo deve responder e porque há diversas variações no próprio indivíduo ao longo do tempo, seja em relação ao seu humor ou à sua fadiga, por exemplo. Percebe-se, então, uma íntima relação entre aspectos contextuais e as estratégias adotadas na decisão das pessoas (Eek \& Gärling, 2008). Entretanto, não está claro na literatura quais dimensões da situação afetam o comportamento humano, tampouco o mecanismo comportamental em efeito nestes fenômenos. Algumas dimensões relatadas na literatura são o tipo de consequência (pecuniária, não pecuniária ou hipotética; e.g, Camerer \& Hogarth, 1999; Locey, Jones, \& Rachlin, 2011) e diferenças entre distribuição de ganho ou de perda (e.g., de Dreu, Carnevale, Emans, \& van de Vliert, 1994; de Dreu \& McCusker, 1997).

Para esclarecer a relação entre os aspectos contextuais e as estratégias adotadas nas decisões das pessoas, os jogos econômicos são utilizados buscando compreender os processos de tomada de decisão e de alocação de recursos e oferecendo modelos experimentais tanto para economistas, quanto para psicólogos, principalmente no contexto de interação social complexa (Kennelly \& Fantino, 2007). Tais jogos simplificam a situação em um cenário artificial, possibilitando a investigação das variáveis em questão, como o Jogo do Ultimato e o Jogo do Ditador (Fantino \& Kennelly, 2009; Forsythe, Horowitz, Savin, \& Sefton, 1994; Güth \& Tietz, 1990; Güth \& van Damme, 1998), nos quais há um distribuidor que aloca recursos para si para e para o receptor. No Jogo do Ditador, esse receptor não tem poder de decisão e apenas recebe a oferta do ditador, mas no Jogo do Ultimato ele pode rejeitar a proposta do distribuidor, o que acarretaria perdas para ambos jogadores.

Para Bowles (2004), os jogos econômicos são uma forma de modelar interações estratégicas, as quais seriam situações em que as consequências das ações dos indivíduos dependem das ações tomadas por outros, sendo esta interdependência mútua reorganizada por aqueles envolvidos. A Teoria Comportamental de Jogos é uma das abordagens que estudam tal fenômeno. Segundo Camerer (2003), esta teoria se apoia no que as pessoas de fato fazem ao jogar, tornando-as menos dependentes de suposições e, assim, contribuindo para a extensão do conhecimento sobre o tema. Assim, o controle experimental é particularmente importante, pois os jogadores essencialmente se comportam de maneira a fazer escolhas, e sofrem o efeito dos valores das consequências das escolhas e de outras variáveis, tais como sua história passada, em termos do conhecimento já adquirido e experiência específica com o jogo.

O jogo trabalhado no presente estudo, o Sharing Game, investiga a tomada de decisão relacionada à alocação de recursos e foi desenvolvido recentemente por Kennelly e Fantino (2007). Neste jogo, os participantes alocam recursos para eles mesmos e para outro jogador, que não tem poder de decisão e não é identificado, e que, na verdade, não existe. A partir das distribuições de escolhas dos participantes, é possível identificar as estratégias mais frequentemente adotadas por eles. Dessa forma, o Sharing Game mostrou-se 
útil para estudar o fenômeno da generosidade e do altruísmo, o qual, segundo Fantino e Stolarz-Fantino (2002), é de particular interesse dentro do âmbito da cooperação, por sua importância social e de sobrevivência da espécie.

Ao longo do Sharing Game são dadas aos participantes vinte tentativas ou rodadas, nas quais eles devem escolher entre duas opções: em uma delas ele recebe um valor e o outro jogador menos do que ele (opção não ótima), na outra ele recebe um valor maior, mas o outro jogador recebe ainda mais que ele (opção ótima). Assim, este jogo é um paradigma de escolha forçada com duas opções, em que as decisões do participante distribuidor, em relação às alocações de recursos, determinam o que ele irá receber, bem como o que o outro participante receberá. As duas opções de cada escolha são sempre numericamente simétricas, de forma que o valor absoluto da diferença entre os resultados para o Participante 1 e o Participante 2 é o mesmo para ambas as opções. Um exemplo das escolhas é: o participante pode escolher receber $\$ 5$, enquanto o outro participante recebe $\$ 3$, ou o participante pode escolher receber $\$ 7$, enquanto o outro participante recebe $\$ 9$. Assim, a opção ótima é aquela que produz a maior quantia para o Participante 1, e a não ótima, também chamada de competitiva, oferece uma vantagem competitiva em relação ao outro participante. Dessa forma, com o Sharing Game é possível identificar aqueles participantes cujas alocações maximizam seus ganhos e aqueles cujas alocações resultam em estabelecer uma vantagem relativa sobre o outro participante (o receptor; Fantino \& Kennelly, 2009).

Ao longo das tentativas, além de escolher somente a maioria das opções ótimas, o participante pode escolher a maiorias das opções não ótimas, para que o outro jogador tenha menos recursos que ele, ou alternar entre ambas as opções, para que ele e o outro jogador fiquem com a quantidade de recursos semelhante. Neste jogo, os autores facilitaram esta última estratégia repetindo as opções em tentativas consecutivas, isto é, opções idênticas eram oferecidas na primeira e na segunda tentativas, na terceira e quarta tentativas, e assim por diante. Então, se o participante alternasse a escolha (escolhesse a opção ótima e depois escolhesse a não ótima) em um par de tentativas consecutivas, ele e o outro jogador ficariam com a mesma quantidade de pontos. Vale lembrar que os estudos anteriores com o Sharing Game envolviam alocações de dinheiro real ou dinheiro hipotético (Fantino \& Kennelly, 2009; Kennelly \& Fantino, 2007).

Nas condições experimentais realizadas por Kennelly e Fantino (2007), somente 49\% das escolhas foram otimizadas. Seus resultados gerais apresentaram uma distribuição trimodal para cada uma dessas três estratégias básicas de respostas entre os participantes. Entretanto, uma análise mais minuciosa revelou que a distribuição trimodal era ilusória e que os padrões de preferência não eram estáveis, o que é de acordo com o que van Lange e Joireman (2010) propõem, isto é, a pessoa possui probabilidades diferentes de se comportar de maneira cooperativa, individualista e igualitária. Kennelly e Fantino (2007), em seguida, realizaram outra condição, atentando para o fato de eliminar qualquer sugestão de competição das instruções do jogo. Feito isso, as escolhas competitivas foram reduzidas drasticamente e os resultados gerais mostraram uma distribuição bimodal, com as modas no padrão igualitário, sendo seguido pelo padrão ótimo.

Fantino e Kennelly (2009), também eliminaram qualquer sugestão de competição e realizaram um estudo com um delineamento intrassujeitos, encontrando que os participantes realizaram mais escolhas ótimas nas condições monetárias do que nas condições não monetárias. No seu Experimento 1, quando o jogo envolveu dinheiro real, a opção ótima foi escolhida em $75,4 \%$ das escolhas, e quando envolveu dinheiro hipotético ela foi realizada em $66,1 \%$ das escolhas, sendo que tal diferença foi significativa. Em ambos os experimentos, aproximadamente a quarta parte das alocações foram em opções não ótimas, oferecendo evidência adicional de que decisões sobre alocações em jogos econômicos não são feitas exclusivamente em função da maximização de recursos (e.g., Camerer \& Hogarth, 1999; Zizzo \& Oswald, 2001), o que sugere que variáveis contextuais - como características do jogo, recompensas financeiras hipotéticas ou 
reais - podem e afetam o comportamento em situações de escolha (e.g., Fantino, 2001; Fantino $\&$ Stolarz-Fantino, 2002; Grace, 1994).

A Psicologia geralmente utiliza incentivos hipotéticos, enquanto economistas insistem que resultados significativos só podem ser coletados apenas com incentivos financeiros reais (Hertwig \& Ortmann, 2001). Em uma revisão bibliográfica realizada por Camerer e Hogarth (1999), foi encontrado que em alguns tipos de jogos econômicos o comportamento dos participantes é facilitado por incentivos financeiros enquanto isso não ocorre em outros jogos. Já Locey et al. (2011) não encontraram diferenças significativas entre a utilização de dinheiro hipotético e dinheiro real em dois experimentos, um envolvendo uma variação do Dilema do Prisioneiro e outro envolvendo o desconto social (social discounting). Estes autores acreditam que dinheiro real impõe um contexto de maximização monetária que pode diferir do contexto do mundo real, o qual é de interesse para o pesquisador. Um participante em um laboratório que tente imaginar o que ele faria em uma situação real hipotética pode ser mais próximo da realidade do que o participante voltar-se simplesmente para a maximização da sua recompensa monetária. Dessa forma, eles defendem que a utilização de dinheiro real pode criar uma exigência implícita de maximizar a recompensa monetária e ignorar outras dimensões do jogo econômico que possam ser presentes nas situações da vida real.

Por conta desses resultados distintos, ainda são necessários estudos que investiguem o uso de incentivo real e de incentivo hipotético, sendo esta uma discussão ainda em andamento nos estudos de jogos econômicos. Como alternativa para o uso de dinheiro hipotético e de dinheiro real, Fantino, Gaitan, Kennelly e Stolarz-Fantino (2007) utilizaram tempo livre de uma tarefa tediosa como reforçador no Jogo do Ultimato. Nesse estudo, participantes tenderam a manter um montante bem maior dos recursos na condição de tarefa tediosa do que quando era dinheiro hipotético e também quando era dinheiro real. Porém, os autores ressaltam a dificuldade de comparar diferentes tipos de incentivos utilizados nos jogos.
Os jogos econômicos também podem envolver distribuição de perdas. No trabalho de de Dreu e McCusker (1997), por exemplo, era dito aos participantes na condição de ganho que eles iniciariam a atividade sem pontos e que ganhariam pontos quando tomassem decisões; aos participantes na condição de perda, era dito que eles iniciariam com determinada quantia de pontos e que perderiam esses pontos quando tomassem decisões. Os participantes entravam em contato com um dilema social, no qual poderiam desertar ou cooperar. Foi encontrado que os participantes considerados previamente como cooperadores cooperaram mais em um esquema de perda do que em um esquema de ganho, enquanto os considerados previamente como individualistas cooperaram menos em um esquema de perda do que em um esquema de ganho. De Dreu et al. (1994) e Tversky e Kahneman (2009) são outros exemplos de estudos com a relação entre ganho e perda.

O presente estudo consistiu em um trabalho exploratório e propôs investigar o Sharing Game em diferentes contextos a fim de verificar como se distribuiriam os padrões de escolha dos participantes. Há uma série de trabalhos na área de Tomada de Decisão com jogos econômicos diversos (e.g., Jogo do Ditador, Jogo do Ultimato, Dilema do Prisioneiro etc.) que têm manipulado variáveis como a distribuição de dinheiro hipotético e de dinheiro real (e.g., Camerer \& Hogarth, 1999; Locey et al., 2011); a distribuição de perda de recurso (e.g., de Dreu et al., 1994; de Dreu \& McCusker, 1997; Tversky \& Kahneman, 2009); a distribuição de tempo (e.g., Fantino et al., 2007) e o valor inicial disponibilizado ao receptor (endowment; e.g., Solnick \& Hemenway, 1998). Contudo, até o momento, destas variáveis apenas o dinheiro hipotético e dinheiro real foram trabalhados no Sharing Game (Fantino \& Kennelly, 2009; Kennelly \& Fantino, 2007).

Considerando essa literatura prévia de jogos econômicos, foram manipuladas neste trabalho as seguintes variáveis independentes: natureza do incentivo (dinheiro real ou hipotético); tempo para uma tarefa tediosa; ganhos e perdas de recurso; e o endowment inicial do Participante 2 (ele iniciar o jogo com determinada quantia de pontos). Diferentemente do que foi realizado por 
Fantino e Kennelly (2009) e Kennelly e Fantino (2007), o Sharing Game foi adaptado para torná-lo aplicável em grupos de participantes em sala de aula. Outra diferença foi referente à ordem da apresentação das tentativas, pois nos estudos anteriores as escolhas eram apresentadas consecutivamente aos pares. Entretanto, neste estudo, as opções se repetiam somente depois de todas terem sido apresentadas.

Tendo isso em vista, o objetivo geral foi investigar o Sharing Game em diversos contextos (Ganho de Dinheiro Hipotético e de Dinheiro Real; Perda de Dinheiro Hipotético e de Dinheiro Real; Participante 2 Iniciando o Jogo com Pontos, com Dinheiro Hipotético e com Dinheiro Real e Tempo para Realizar uma Tarefa Tediosa), através da realização de quase experimentos em diferentes grupos de estudantes universitários, para comparar as distribuições de escolhas realizadas, de acordo com as seguintes estratégias: competitiva, igualitária e ótima.

\section{Método}

\section{Participantes e Materiais}

No total, participaram 233 universitários de uma universidade pública" de diversos cursos de graduação, como Engenharia Florestal, Física
Médica, Serviço Social, Direito, Enfermagem e Administração, sendo 121 (52\%) do sexo feminino. A faixa etária variou de 16 a 48 anos, tendo como média 22 anos $(D P=6)$. Ao todo, houve dez missings nas sete condições realizadas, sendo que houve, em média, 33 participantes em cada uma delas.

Os materiais utilizados foram blocos que continham as instruções e as tentativas; folhas de resposta e canetas.

\section{Delineamento Experimental}

O presente trabalho consistiu em sete condições com a realização de quase experimentos, pois as turmas foram selecionadas por conveniência, não havendo uma distribuição aleatória dos estudantes que participaram nas diversas condições. Foi utilizado um delineamento entre grupos para verificar o efeito das diferentes variáveis contextuais no comportamento de distribuição de recursos.

\section{Procedimento}

Conforme verificado na Tabela 1, foram realizadas sete condições com o Sharing Game (Kennelly \& Fantino, 2007), cada uma em diferentes salas com alunos de diversos cursos e nem sempre a sala possuía alunos de apenas um curso.

Tabela 1

Características das Condições Experimentais

\begin{tabular}{ccc}
\hline Condição & Característica & $N$ \\
\hline 1 & Ganho de Dinheiro Hipotético & 35 \\
2 & Ganho de Dinheiro Real & 33 \\
3 & Perda de Dinheiro Hipotético & 30 \\
4 & Perda de Dinheiro Real & 33 \\
5 & Participante 2 Iniciando o Jogo com Pontos, com Din. Hip. & 36 \\
6 & Participante 2 Iniciando o Jogo com Pontos, com Din. Real & 34 \\
7 & Tempo para Realizar uma Tarefa Tediosa & 32 \\
\hline
\end{tabular}

Vinte tentativas (dois blocos de dez tentativas) eram apresentadas, uma de cada vez, com duas opções de escolha, diante das quais os participantes deveriam escolher apenas uma. Há uma diferença em relação ao estudo de Kennelly e Fantino (2007), pois nele, ao longo das vinte tentativas, as escolhas eram sempre apresentadas aos pares (e.g., opção 30/45 versus opção $25 / 10$ eram apresentadas duas vezes consecutivamente), o que possibilitava uma terceira possibilida- 
de de escolha: combinar os seus ganhos com os do outro. Entretanto, no presente estudo optou-se por realizar esta repetição de forma diferente, isto é, as opções não eram apresentadas aos pares, elas se repetiam somente depois de todas terem sido apresentadas. A partir da $11^{\text {a }}$ tentativa, eram repetidas as dez primeiras, na mes- ma ordem. Tal alteração foi realizada porque se acreditou que talvez o participante pudesse achar entediante responder a duas tentativas idênticas consecutivamente. Apesar da diferença, isso também permitiu a possibilidade de combinar as distribuições. Na Tabela 2, há as tentativas, apresentadas para os participantes, com a quantidade de recursos a serem divididos.

Tabela 2

Conjunto de Escolhas Apresentadas ao Distribuidor (Participante 1) no Sharung Game

\begin{tabular}{cccc}
\hline \multicolumn{2}{c}{ Opção Ótima } & \multicolumn{2}{c}{ Opção Competitiva } \\
\hline $\begin{array}{c}\text { Participante 1 } \\
\text { (distribuidor) recebe }\end{array}$ & $\begin{array}{c}\text { Participante } 2 \\
\text { (receptor) recebe }\end{array}$ & $\begin{array}{c}\text { Participante 1 } \\
\text { (distribuidor) recebe }\end{array}$ & $\begin{array}{c}\text { Participante 2 } \\
\text { (receptor) recebe }\end{array}$ \\
\hline 30 & 40 & 20 & 10 \\
30 & 35 & 25 & 20 \\
35 & 45 & 25 & 15 \\
40 & 55 & 25 & 10 \\
45 & 65 & 25 & 5 \\
30 & 45 & 25 & 5 \\
35 & 45 & 15 & 10 \\
40 & 50 & 20 & 20 \\
40 & 45 & 25 & 20 \\
40 & 50 & 30 & 5 \\
\hline
\end{tabular}

Os estudantes eram convidados a participar voluntariamente e respondiam em grupo nas salas de aula da respectiva universidade. Porém, era solicitado que eles não conversassem durante a tarefa e que respondessem individualmente. Para cada participante, era fornecida uma folha de resposta, na qual os participantes marcariam suas escolhas, e também um bloco que continha as instruções do jogo e as vinte tentativas, as quais eram apresentadas sucessivamente, uma de cada vez (Figura 1). Era solicitado que os participantes não voltassem à tentativa anterior, isto é, à página anterior, quando já marcassem a sua escolha na folha de resposta.

A atividade somente era iniciada após o as instruções serem lidas para todos e após possíveis dúvidas serem esclarecidas, tendo o participante entendido como a atividade deveria ser realizada. Após esse momento, os participantes não podiam tirar mais dúvidas. Quando acabavam, era solicitado que permanecessem em silêncio até todos acabarem e o material ser recolhido. Em todas as condições, o participante distribuía os recursos entre ele e um suposto Participante 2, que, na verdade, não existia. Era dito que este segundo participante fazia parte de outra turma e não tinha como ser identificado. Também era explicado ao participante que somente ele tinha o poder da decisão.

Houve a condição Ganho de Dinheiro Hipotético $(n=35)$, na qual os participantes distribuíam pontos sem qualquer valor monetário e a condição Ganho de Dinheiro Real $(n=33)$, na qual os participantes distribuíam pontos que poderiam ser trocados por bilhetes para participar de um sorteio no valor de $\mathrm{R} \$ 50,00$, que ocorreria ao final do jogo. No fim desta condição, eram explicados brevemente os objetivos da pesquisa e que, na verdade, todos os participantes teriam iguais chances no sorteio. Este sorteio foi utilizado da mesma forma nas demais condições que envolveram dinheiro real. 


\section{Você escolhe:}

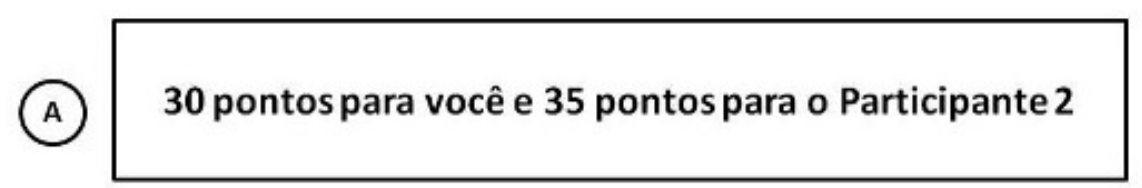

OU

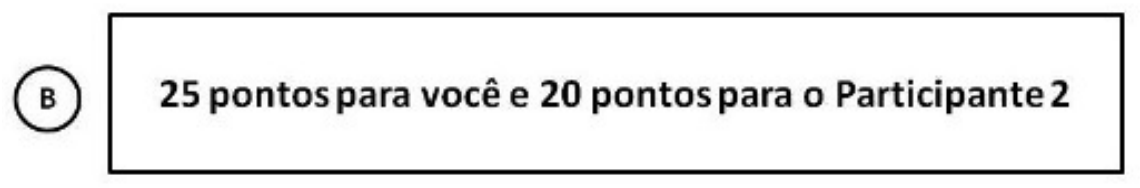

Figura 1. Exemplo de tentativa apresentada aos participantes.

Nas condições Perda de Dinheiro Hipotético $(n=30)$ e Perda de Dinheiro Real $(n=33)$, era apresentado aos participantes que eles, e os supostos Participantes 2, iniciavam a atividade com 1.000 pontos cada um. Ao fim da atividade, a quantidade de pontos que cada um teria seria esses 1.000 pontos reduzidos pelo total de pontos obtidos. Por exemplo, se ao fim da atividade o participante obtivesse a partir dos pontos que distribuiu para si um total de 730 pontos, ele ficaria, na verdade, com 270 pontos $(1.000-730$ $=270)$. Assim, percebe-se que quanto menos pontos o distribuidor escolhesse para si nas tentativas, com mais pontos ele ficaria ao final do jogo. Dessa forma, há uma inversão no que diz respeito às opções que eram consideradas ótimas e não ótimas. As opções ótimas seriam aquelas que oferecessem ao participante uma menor redução dos seus recursos e ao Participante 2 uma redução ainda menor. As não ótimas, por sua vez, seriam aquelas que oferecessem ao participante uma maior redução dos seus recursos e ao Participante 2 uma redução ainda maior, isto é, quando essa opção fosse escolhida significaria que o participante estaria disposto a ficar com menos pontos ao fim do jogo, desde que o Participante 2 ficasse com menos ainda.

Nas condições Participante 2 Iniciando o Jogo com Pontos, com Dinheiro Hipotético $(n=36)$ e Participante 2 Iniciando o Jogo com
Pontos, com Dinheiro Real $(n=34)$ foi informado aos participantes que os supostos Participantes 2 já tinham realizado esta mesma tarefa anteriormente, e que tinham acumulado determinada quantidade de recursos. Em cada folha de resposta, havia, aleatoriamente, que o Participante 2 possuía 265, 275, 885 ou 895 pontos. Essa diferença foi trabalhada para que se pudesse averiguar se essa quantidade de pontos do Participante 2 teria algum efeito nos resultados. Entretanto, como em ambas as condições não houve diferença significativa entre tais quantidades de pontos, os dados foram agrupados.

Por fim, na condição Tempo para uma Tarefa Tediosa $(n=32)$, era dito aos participantes que, após o término da aula, eles seriam levados a um laboratório do curso de Psicologia para assistirem a um vídeo de 35 segundos, repetidas vezes, por no máximo 12 minutos. A partir de suas alocações de segundos entre o participante e o receptor, ele poderia reduzir esse tempo para si e para o receptor. Quando todos acabaram, foi solicitado que, em uma escala de 1 a 5 , eles respondessem na folha o quanto acharam a atividade do vídeo entediante, sendo 1 "legal" e 5 "chato". Após responderem essa pergunta, era explicado que não seria preciso assistir a esse vídeo.

Procedimento para Registro e Análise de Dados. As respostas para cada tentativa foram registradas por todos os participantes na folha 
de resposta que recebiam no início do procedimento. As escolhas foram registradas como: (a) ótima (quantidade máxima de pontos/segundos para si e, incidentalmente para o segundo participante) ou (b) não ótima (quantidade mínima de pontos/segundos para si e, incidentalmente para o segundo participante). No caso das condições envolvendo perdas, isso é invertido, pois a ótima era aquela com quantidade mínima de pontos. Para a análise do comportamento de escolha, a variável dependente foi o número absoluto e a porcentagem das tentativas nas quais os participantes escolheram a opção ótima. As variáveis independentes investigadas referiram-se a: dinheiro hipotético, dinheiro real, tempo para uma tarefa tediosa, perda ou ganho e Participante 2 iniciando o jogo com pontos.

Em cada condição, os participantes foram divididos entre aqueles que adotaram a estratégia competitiva - quando escolhiam de $0 \%$ a 33\% das opções ótimas ao longo das vinte tentativas; a estratégia igualitária - quando escolhiam de $34 \%$ a $66 \%$ das opções ótimas; e a estratégia ótima - quando escolhiam de $67 \%$ a $100 \%$ das opções ótimas. Apesar de esta divisão em tais intervalos levar em consideração as estratégias presentes no Sharing Game, ela não é encontrada nos estudos anteriores envolvendo este jogo (Fantino \& Kennelly, 2009; Kennelly $\&$ Fantino, 2007). Ela foi realizada no presente trabalho como uma forma de comparar tais estratégias em todas as condições. Pelo fato das con- dições experimentais contarem com amostras de diferentes tamanhos, foram retiradas as porcentagens dos participantes que adotaram cada uma das estratégias de escolha. Dessa forma, é possível saber qual a porcentagem de participantes de cada uma das três estratégias em cada condição realizada.

Em seguida, foi realizado um teste não-paramétrico, o qui-quadrado, para verificar a associação entre: (a) as condições que envolviam dinheiro hipotético (Condição 1, Condição 3, e Condição 5); (b) as condições que envolviam dinheiro real (Condição 2, Condição 4, e Condição 6); (c) as condições que envolviam dinheiro hipotético ou dinheiro real (e.g.: Condição $1 \mathrm{e}$ Condição 2); (d) e a que envolvia alocação de tempo (Condição 7). O nível de significância adotado foi $p<0,05$.

\section{Resultados}

Comparando todas as condições, percebe-se que a porcentagem da estratégia competitiva foi maior na Condição 5 (35\%) e na Condição $6(30 \%)$, e menor na Condição $2(12 \%)$ e na Condição 7 (12\%). Já a porcentagem da estratégia igualitária foi maior na Condição 7 (81\%), e menor na Condição $2(45 \%)$ e na Condição 5 $(50 \%)$. Por fim, a porcentagem da estratégia ótima foi maior na Condição $2(42 \%)$ e menor na Condição 7 (6\%) e na Condição 6 (7\%). Tais dados podem ser observados na Figura 2.

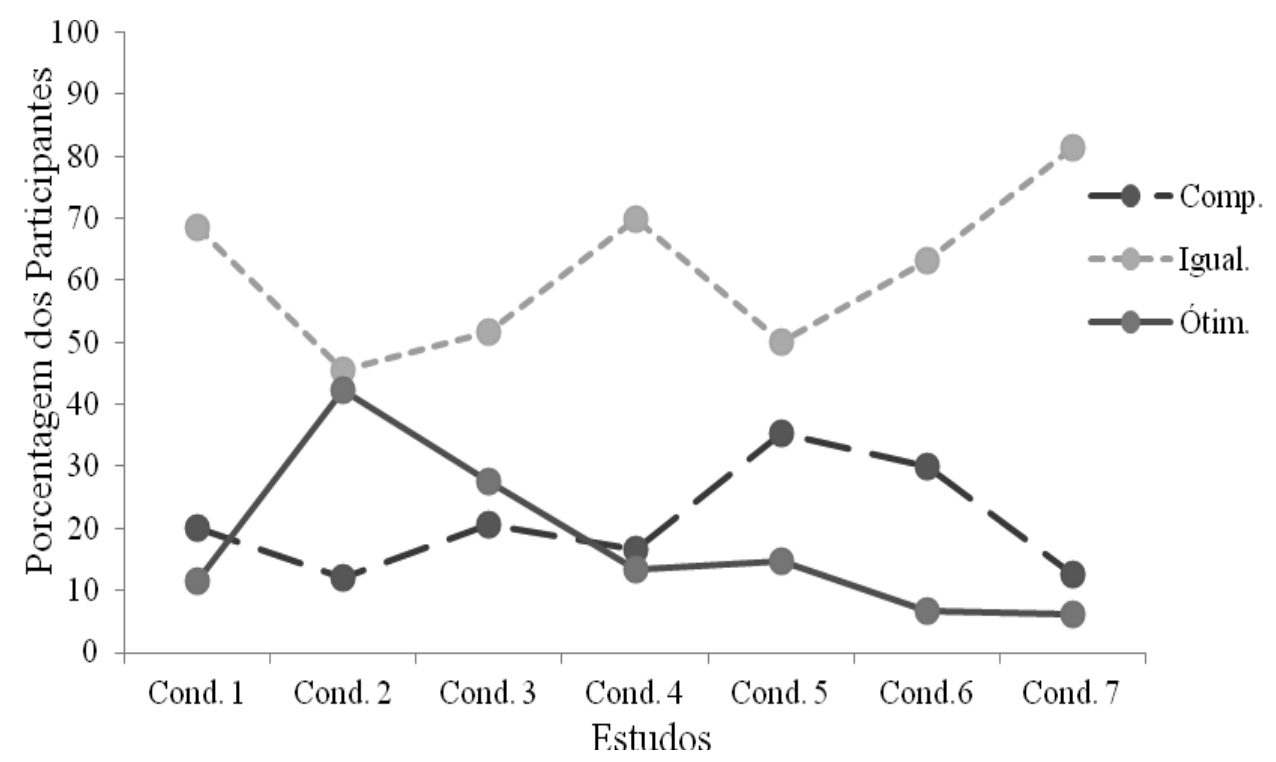

Figura 2. Porcentagem dos participantes que adotaram as estratégias competitiva, igualitária e ótima, em todas as condições. 
A partir destes dados, é visto que os participantes optaram mais frequentemente por distribuir de forma igual quando a atividade envolveu tempo para algo desagradável. Foi verificado que a maioria considerou a tarefa como sendo entediante, pois a média da medida de tédio que os participantes responderam foi acima da média da escala $(M=3,75, D P=1,1)$. Alguns participantes desta condição justificaram que distribuíram igualitariamente o tempo porque não queriam realizar sozinhos a atividade tediosa. Acredita-se que outros participantes também possam ter pensado da mesma forma. Por sua vez, os participantes foram mais individualistas, isto é, realizaram escolhas ótimas mais frequentemente quando a atividade envolveu ganho de dinheiro real, em uma comparação entre condições. Finalmente, os participantes foram mais competitivos quando a atividade iniciou com o suposto Participante 2 já tendo jogado anteriormente e já começado com determinada quantidade de recursos, sendo mais frequentes quando a atividade envolvia dinheiro hipotético.

Ainda é interessante apresentar que a porcentagem de cada estratégia foi retirada em relação a todos os participantes destas condições. Assim, desconsiderando os missings, dos 223 participantes, $21,1 \%$ realizou a estratégia competitiva, $61,4 \%$ a estratégia igualitária e $17,5 \%$ a estratégia ótima. Com isso, é possível comprovar o que já é evidente na Figura 2: a estratégia igualitária prevaleceu em todas as condições. Parece, então, que a maioria dos participantes optou por distribuir os recursos entre si e entre outro participante, que era não visto e não tinha poder de decisão, de forma que ambos ficassem com quantidades semelhantes de recursos. Estes resultados podem indicar que o Sharing Game permite investigar o fenômeno da generosidade entre os indivíduos e faz com que se questione porque a estratégia igualitária é tão predominante.

A partir da porcentagem de escolhas ótimas ao longo das 20 tentativas, os participantes foram categorizados em uma das três estratégias (competitiva, igualitária e ótima). Foi realizado, então, um teste não paramétrico, o qui-quadrado, comparando as condições experimentais a partir da porcentagem de participantes que adotaram cada uma das três estratégias. Assim, as condições foram comparadas aos pares, investigando a relação entre duas variáveis categóricas: estratégia adotada e condição. Ao todo, foram investigadas 21 relações, entretanto, foi encontrada uma diferença significativa apenas entre as condições Ganho de Dinheiro Hipotético e Ganho de Dinheiro Real $\left(\mathrm{x}^{2}=6,74, g l=2 ; p=0,034\right)$, sendo que $42,4 \%$ dos participantes da condição Ganho de Dinheiro Real adotaram a estratégia ótima e apenas $14,3 \%$ dos participantes da outra condição adotaram esta estratégia.

\section{Discussão}

Os jogos econômicos trabalham com as estratégias envolvidas nos processos de tomada de decisão presentes nas interações sociais, transferindo-se as principais características de tais interações para o jogo (Bowles, 2004). O objetivo deste trabalho foi investigar um jogo econômico fundamentado na Análise do Comportamento, o Sharing Game (Kennelly \& Fantino, 2007), o qual foi estudado em diversos contextos, a fim de poder comparar as diferentes distribuições de escolhas pelos participantes, de acordo com as três estratégias apresentadas (competitiva, igualitária e ótima). Para isso, foram realizadas sete condições quase experimentais, sendo que em cada uma destas condições foram manipuladas as seguintes variáveis: dinheiro hipotético, dinheiro real, tempo para uma tarefa tediosa, jogo envolvendo ganhos, jogo envolvendo perdas, e o endowment do Participante 2.

O presente trabalho realizou algumas adaptações do Sharing Game, não sendo, portanto, uma replicação direta dos trabalhos de Fantino e Kennelly (2009) e de Kennelly e Fantino (2007), pois ele foi realizado em grupo, em salas de aula e, enquanto estes autores apresentavam uma mesma tentativa aos pares, nas condições aqui realizadas optou por apresentar um bloco de 10 tentativas diferentes e depois este mesmo bloco ser repetido. Isso foi realizado porque se acreditou que o participante pudesse achar entediante responder a duas tentativas idênticas consecutivamente. Além disso, como foi mostrado anteriormente, neste trabalho, para ser realizada 
uma comparação entre as condições, as escolhas dos participantes foram agrupadas de acordo com as escolhas ótimas realizadas nestas três estratégias: competitiva ( $0 \%$ a $33 \%$ de escolhas ótimas), igualitária (34\% a 66\%) e ótima (67\% a $100 \%$ ). Esta divisão não é encontrada nos trabalhos anteriores do Sharing Game, mas acredita-se que ela permitiu realizar comparações relevantes das tomadas de decisão dos participantes entre as condições desenvolvidas.

Quando foram analisadas as distribuições de escolha dos participantes, verificou-se que em todas as condições a estratégia igualitária, aquela em que o participante distribui suas escolhas de maneira que o Participante 2 fique com quantidade de recursos semelhante a dele, foi a predominante. Ainda que, em relação às demais condições, na Condição 2 tenha existido um maior número de participantes que optaram pela estratégia ótima, ainda assim a estratégia igualitária teve uma frequência considerável em tal condição.

É válido lembrar que van Lange e Joireman (2010) apresentam que estas escolhas dependem tanto das variáveis individuais quanto das variáveis situacionais, ou seja, na verdade, a pessoa possui determinada probabilidade de adotar uma estratégia competitiva, igualitária, etc., a qual depende destas variáveis. Assim sendo, acredita-se que uma pessoa cooperativa é uma pessoa que tem uma probabilidade maior de comportar-se cooperativamente e uma probabilidade relativamente menor de comportar-se como individualista ou competitivo. Estes autores propõem, portanto, flexibilidade e adaptação do comportamento do indivíduo, o que é de acordo com o que Eek e Gärling (2008) apresentam, pois eles também acreditam que fatores situacionais afetam as escolhas dos indivíduos, como por exemplo o tipo de jogo econômico a ser desenvolvido, as características do indivíduo com quem ocorre a interação, o número de pessoas envolvidas, dentre outros.

Fantino e Kennelly (2009) encontraram uma diferença entre a utilização de dinheiro hipotético e de dinheiro real, pois quando este último foi utilizado no jogo, no Experimento 1, 75,4\% das escolhas dos participantes foram otimiza- das, contra $66,1 \%$ quando foi utilizado dinheiro hipotético. Apesar de ser com valores distintos aos de Fantino e Kennelly (2009), esta diferença também foi encontrada entre as Condições 1e 2. Quando dinheiro real foi utilizado, $63 \%$ das escolhas foram ótimas. E, no caso do dinheiro hipotético, apenas $44 \%$ das escolhas foram otimizadas. Além disso, quando os participantes foram divididos de acordo com a estratégia adotada, foi encontrada uma diferença significativa entre estes dois grupos, com a Condição 1 tendo uma maior porcentagem $(42,4 \%)$ de participantes que adotaram a estratégia ótima. Assim, mesmo que no presente trabalho tenham sido utilizados pontos para o sorteio de um prêmio e não pagamento em moeda corrente, os dados foram semelhantes aos de Fantino e Kennelly (2009) em relação à distribuição de ganho de dinheiro hipotético e de ganho de dinheiro real.

Geralmente, pesquisas na área de Psicologia utilizam incentivos hipotéticos, o que é diferente do que os economistas defendem, pois eles acreditam que resultados significativos só podem ser coletados apenas com incentivos financeiros reais (Hertwig \& Ortmann, 2001). Os resultados encontrados por Fantino e Kennelly (2009), por Kennelly e Fantino (2007) e pelo presente trabalho, relativo às Condições 1 e 2 , mostraram que os participantes nas condições monetárias realizaram mais escolhas ótimas do que aqueles em condições não monetárias, o que revela um efeito da natureza do incentivo nas alocações de recursos realizadas pelos participantes. Entretanto, nas outras quatro condições que tentaram comparar o uso de dinheiro hipotético e o uso de dinheiro real (Condições 3, 4, 5 e 6), os resultados foram diferentes. Neles, além de a diferença ter sido menor entre o uso de dinheiro hipotético e dinheiro real, quando dinheiro hipotético foi utilizado, houve uma porcentagem um pouco maior de escolhas ótimas do que quando foi utilizado dinheiro real.

Os dados dessas quatro últimas condições vão de encontro tantos aos resultados das Condições 1 e 2, quanto aos resultados dos trabalhos de Camerer e Hogarth (1999), e aos resultados de Fantino e Kennelly (2009), que encontraram que os participantes agem mais generosamente $\mathrm{e}$ 
assumem mais riscos quando é utilizado dinheiro hipotético. Pode ter ocorrido uma interação entre essas duas variáveis (dinheiro hipotético e dinheiro real) e as outras variáveis em questão (perda de recurso e o Participante 2 iniciar o jogo já com determinada quantia de pontos), contribuindo para essa diferença encontrada. $\mathrm{O}$ Participante 2 já iniciar o jogo com pontos pode ter levado, por exemplo, a uma diminuição do valor reforçador do dinheiro real, fazendo com que a estratégia ótima tenha tido uma menor porcentagem de participantes que a adotaram.

Entretanto, tais resultados estão de acordo com o trabalho desenvolvido por Locey et al. (2011), no qual os autores não encontraram diferenças significativas entre a utilização de dinheiro hipotético e dinheiro real em dois experimentos realizados. Estes autores, por conta de não terem encontrado esta diferença, defendem que é melhor utilizar dinheiro hipotético do que dinheiro real, pois quando este último é utilizado o participante pode focar em maximizar sua quantia monetária, deixando de lado outras características importantes do jogo.

Outro recurso manipulado no presente trabalho foi tempo para realizar uma tarefa tediosa. Esta condição foi realizado com base em Fantino et al. (2007), que realizaram algo semelhante com o Jogo do Ultimato e descobriram que a condição de tarefa tediosa levou a uma maior retenção dos recursos do que a condição de dinheiro real, isto é, os participantes foram mais individualistas. Entretanto, na Condição $7 \mathrm{com}$ o Sharing Game, não houve grande quantidade de escolhas ótimas, sendo a estratégia igualitária a predominante. Os resultados desta condição também não diferiram significativamente com as demais condições que envolviam alocação de dinheiro. De qualquer forma, Fantino et al. (2007) atentam para a dificuldade de comparar diferentes tipos de recompensas, isto é, o quanto uma determinada quantia de dinheiro vai representar de tempo depende do contexto e do indivíduo. De fato, ainda não está claro na literatura, entretanto, como comparar resultados obtidos utilizando tempo como recurso a ser distribuído.

Como já explicado, os participantes foram agrupados em uma das três estratégias para ser possível obter uma nova visão dos dados das sete condições e compará-las entre si. Em relação ao uso de dinheiro hipotético, a condição envolvendo perda foi a que teve maior percentual de participantes que realizaram otimização, e a condição envolvendo ganho foi a que teve maior percentual daqueles que adotaram a estratégia igualitária. Assim, pode-se interpretar que aparentemente a condição com perda, quando envolveu dinheiro hipotético, influenciou para que a maioria dos participantes fosse individualista, isto é, realizasse com maior frequência a escolha ótima, aquela que lhe oferecia menor perda. Já em relação ao uso de dinheiro real, a condição envolvendo ganho foi a que teve maior percentual de participantes que realizaram a estratégia ótima, e a condição com perda foi a que teve maior percentual daqueles que adotaram a estratégia igualitária. Porém, nenhuma dessas diferenças foi significativa de acordo com o teste estatístico realizado.

Uma última variável trabalhada foi o Participante 2 iniciar o jogo com pontos, enquanto o distribuidor iniciava com nada. As Condições 5 e 6 foram as únicas que forneciam uma informação prévia sobre eles. Deve-se atentar que este procedimento pode ter funcionado como uma modificação no contexto de escolha que alterou o valor reforçador dos recursos empregados. Dessa forma, a relevância destas condições pode ser constatada no fato de os demais trabalhos com o Sharing Game não incluírem informação alguma sobre o Participante 2 para os distribuidores. Assim, cada um poderia imaginá-lo de um modo diferente, podendo the atribuir características diversas. Foi levantada a hipótese de que o valor do estímulo utilizado (pontos com ou sem valor monetário) aumentaria em função do que o outro participante teria.

Em relação a essa mudança no valor reforçador de um estímulo para um indivíduo em função da quantidade deste mesmo estímulo que outros indivíduos possuem, pode-se traçar um paralelo com o que os economistas definem como um bem posicional. É possível definir um bem posicional como um bem cujo valor está relacionado com a forma pela qual ele está distribuído em um grupo de indivíduos. Sendo assim, 
no que concerne a bens posicionais, não são somente os ganhos individuais de um sujeito que importam, mas sim estes ganhos em relação aos ganhos de outros indivíduos (Bowles, 2004). Fazendo uma aproximação com as características do jogo aqui trabalhado, o valor relativo de um bem (no caso do presente estudo, pontos a serem distribuídos) foi alterado devido ao Participante 2 já possuir determinada quantia deste bem, o que aparentemente levou ao distribuidor a uma maior competição para reduzir a vantagem inicial do Participante 2. Comparando com as demais condições, estas duas possuíram o maior percentual de participantes que adotaram a estratégia competitiva, o que corresponde aos resultados de Solnick e Hemenway (1998). Dessa forma, a quantidade de recursos com a qual o Participante 2 iniciava o jogo interferiu na quantidade de recursos que os distribuidores alocaram para si.

Assim, quando o Participante 2 iniciou o jogo com pontos, uma maior quantidade de participantes decidiu por não maximizar os seus ganhos talvez para poder retirar essa vantagem inicial, agindo, dessa forma, de maneira competitiva e obtendo uma menor quantidade de recursos. O percentual foi maior quando foi utilizado dinheiro hipotético do que quando foi realizado dinheiro real, ou seja, aparentemente quando envolveu dinheiro hipotético, os participantes eram mais motivados a realizar a estratégia competitiva, minimizando os seus ganhos, mas aumentando a vantagem relativa ao Participante 2. O Participante 2 iniciar o jogo já com pontos pode ser considerado como uma operação estabelecedora, isto é, um evento ambiental que altera a efetividade reforçadora de um estímulo e que evocam todo comportamento que no passado foi seguido de tal estímulo (Michael, 1993).

Dinheiro real e dinheiro hipotético também poderiam ser interpretados dessa forma. Assim, os pontos obtidos na escolha da alternativa ótima teria uma efetividade reforçadora diferente a depender do tipo de incentivo envolvido (dinheiro hipotético e dinheiro real) e das características da condição (e.g.: Participante 2 iniciar o jogo já com pontos). Isso poderia explicar uma possível diferença do número de escolhas ótimas reali- zadas pelos participantes nos cenários trabalhados. Dessa forma, talvez o valor reforçador do dinheiro real tenha sido alto o suficiente para que eles se importassem menos se o outro participante também estaria ganhando mais, isto é, neste caso a maximização de ganhos era a estratégia mais reforçadora a longo prazo.

Ao interpretar os dados encontrados no presente trabalho, é necessário que suas limitações, sejam levadas em consideração. Primeiramente, há o problema das condições terem sido aplicadas em grupo, em salas de aula, por uma questão de conveniência. Assim sendo, deve ser levado em consideração que os dados encontrados nas condições possuem uma grande influência das próprias características das turmas, como curso, horário em que foi aplicado, período do curso em que os alunos se encontravam, nível de conhecimento e de amizade entre os alunos, dentre outras. A aplicação pode também ter favorecido a influência social entre os participantes pelo simples fato de estarem realizando a tarefa ao lado de outras pessoas. E, mesmo sendo solicitados que não conversassem durante a atividade, alguns trocavam informações entre si ou faziam alguns comentários.

Além disso, nas condições que envolveram perda, é interessante que haja um aprimoramento das instruções para que sejam ainda mais claras e objetivas, possibilitando uma maior compreensão. Todavia, é válido ressaltar que, de acordo com a justificativa que os participantes apresentavam, foram retirados os dados daqueles participantes que claramente relataram uma má compreensão da atividade. Os principais casos de exclusão consistiram quando o participante declarava em sua justificativa que o Participante 2 era seu parceiro e que o a soma dos pontos de ambos seria o que eles ganhariam ao fim do jogo.

Outro ponto é que, apesar das instruções terem esclarecido que todos em uma determinada sessão de aplicação eram Participantes 1 e que os Participantes 2 eram desconhecidos e não estavam presentes, é possível que alguns não tenham entendido devidamente essa informação e que tenham achado que estavam jogando entre seus colegas. Dessa forma, assim como Locey et al. (2011) apresentam em sua pesquisa sobre 
desconto social, o vínculo de amizade entre eles pode ter influenciado a distribuição de escolhas. Por último, é importante destacar que, diferentemente do que Fantino e Kennelly (2009) e Kennelly e Fantino (2007) realizaram, aqui foram trabalhados quase experimentos, não experimentos, o que pode ter sido crucial para as diferenças encontradas entre os trabalhos.

Apesar de suas limitações, os dados obtidos evidenciam que decisões sobre alocações em jogos econômicos não são feitas exclusivamente em função da maximização de resultados (e.g., Camerer \& Hogarth, 1999; Zizzo \& Oswald, 2001), o que sugere que tanto o contexto motivacional como a características pessoais e a experiência influenciam nos padrões de preferência. Para sanar as limitações do presente trabalho, é proposto que pesquisas futuras examinem as variáveis aqui estudadas com um maior rigor experimental, através da aplicação individual e com participantes distribuídos aleatoriamente entre as condições. Também é proposto que haja uma amostra maior, como Fantino e Kennelly (2009) e Kennelly e Fantino (2007) realizaram, para que a visualização da interação entre as variáveis seja mais clara e para a realização de outros testes estatísticos.

Ainda seria interessante trabalhar as diferentes variáveis contextuais em um mesmo grupo de participantes, para verificar como a sua distribuição de escolhas iria mudar ou não ao longo das atividades. Um mesmo participante poderia, por exemplo, realizar o Sharing Game envolvendo ganhos e depois jogar novamente, mas envolvendo perdas. De maneira semelhante, poderiam ser trabalhados consecutivamente dinheiro hipotético e dinheiro real, assim como Fantino e Kennelly (2009) realizaram. Nesses casos, seria necessário pensar em formas de controlar o efeito de exposição das atividades.

Conclui-se que o presente trabalho oferece contribuição para pesquisas futuras sobre altruísmo e generosidade, além de enriquecer a compreensão de interações sociais envolvendo distribuição de recursos. Também indica que as diversas variações encontradas na distribuição das escolhas demonstram que o Sharing Game é sensível às varáveis contextuais em que é aplica- do, podendo ser empregado para o estudo de diferentes dinâmicas comportamentais. Assim, ele não apenas fornece mais dados para as pesquisas do Sharing Game, mas enriquece as pesquisas que trabalham com dinheiro hipotético e dinheiro real, com ganhos e perdas de recursos, com tempo e com bem posicional. Talvez a principal contribuição deste trabalho seja mostrar que o Sharing Game pode ser manipulado de diversas formas e mostrar também que ainda há muito a ser pesquisado em relação às variáveis contextuais utilizadas não somente neste, como nos demais jogos econômicos. Espera-se, então, que este trabalho inspire futuras pesquisas nas áreas aqui abordadas para que os efeitos das variáveis sejam melhor compreendidos.

\section{Referências}

Bowles, S. (2004). Microeconomics: Behavior, institutions and evolution. New York: Russel Sage Foundation.

Camerer, C. F. (2003). Behavioral Game Theory: Experiments in strategic interaction. New York: Russel Sage Foundation.

Camerer, C. F., \& Hogarth, R. M. (1999). The effects of financial incentives in experiments: A review and capital-lavor-production framework. Journal of Risk and Uncertainty, 19, 1-3, 7-42. doi:10.1023/A:1007850605129

De Dreu, C. K., Carnevale, P. J. D., Emans, B. J. M., \& van de Vliert, E. (1994). Effects of gain-loss frames in negotiation: Loss aversion, mismatching, and frame adoption. Organizational Behavior and Human Decision Processes, 60, 90-107. doi:10.1006/obhd.1994.1076

De Dreu, C. K., \& McCusker, C. M. (1997). Gainloss frames and cooperation in two-person social dilemmas: A transformational analysis. Journal of Personality and Social Psychology, 72, 10931106. doi:10.1037/0022-3514.72.5.1093

Eek, D., \& Gärling, T. (2008). A new look at the theory of social value orientations: Prosocials neither maximize joint outcome nor minimize outcome differences but prefer equal outcomes. In A. Biel, D. Eek, T. Gärling, \& M. Gustafsson (Eds.), New issues and paradigms in research on social dilemmas (pp. 10-26). Gotemburgo, Sweden: Springer Science. 
Fantino, E. (2001). Context: A central concept. Behavioural Processes, 54, 95-110.

Fantino, E., Gaitan, S., Kennelly, A., \& Stolarz-Fantino, S. (2007). How reinforcer type affects choice in economic games. Behavioural Processes, 75, 107-114. doi:10.1016/j.beproc.2007.02.001

Fantino, E., \& Kennelly, A. (2009). Sharing the wealth: Factors influencing resource allocation in the Sharing Game. Journal of the Experimental Analysis of Behavior, 91, 337-354. doi:10.1901/jeab.2009.91-337

Fantino, E. J., \& Stolarz-Fantino, S. J. (2002). The role of negative reinforcement; or: Is there an altruist in the house? A commentary on Rachlin's Altruism and selfishness. Behavioral and Brain Sciences, 25, 257-258.

Forsythe, R., Horowitz, J. L., Savin, N. E., \& Sefton, M. (1994). Fairness in simple bargaining experiments. Games and Economic Behavior, 6, 347-369.

Grace, R. C. (1994). A contextual model of concurrent chains choice. Journal of the Experimental Analysis of Behavior, 61, 113-129.

Güth, W., \& Tietz, R. (1990). Ultimatum Bargaining Behavior: A survey and comparison of experimental results. Journal of Economic Psychology, 11, 417-449.

Güth, W., \& van Damme, E. (1998). Information, strategic behavior, and fairness in ultimatum bargaining: An experimental study. Journal of Mathematical Psychology, 42, 227-247.

Hertwig, R., \& Ortmann, A. (2001). Experimental practices in economics: A methodological challenge for psychologists? Behavioral and Brain Sciences, 24, 383-451.

Kennelly, A., \& Fantino, E. (2007). The Sharing Game: Fairness in resource allocation as a function of incentive, gender, and recipient types. Judgment and Decision Makin, 2(3), 204-216.

Locey, M. L., Jones, B. A., \& Rachlin, H. (2011). Real and hypothetical rewards in self-control and social discounting. Judgment and Decision Making, 6(6), 552-564.
Michael, J. (1993). Establishing operations. The Behavior Analyst, 16(2), 191-206.

Shelley, G. P., Page, M., River, P., Yeagley, E., \& Kuhlman, D. M. (2010). Nonverbal communication and detection of individual differences in social value orientation. In R. M. Kramer, A. E. Trenbrunsel, \& M. H. Bazerman (Eds.), Social decision making: Social dilemmas, social values, and ethical judgments (pp. 147-170). New York: Routledge.

Solnick, S. J., \& Hemenway, D. (1998). Is more always better?: A survey on positional concerns. Journal of Economic Behavior \& Organization, 37, 373-383.

Tversky, A., \& Kahneman, D. (2009). Loss aversion in riskless choice: A reference-dependent model. The Quarterly Journal of Economics, 106(4), 1039-1061. doi:10.2307/2937956

Van Dijk, E., Wit, A. P., Wilke, H. A. M., \& de Kwaadsteniet, E. W. (2010). On the importance of equality in social dilemmas. In R. M. Kramer, A. E. Trenbrunsel, \& M. H. Bazerman (Eds.), Social decision making: Social dilemmas, social values, and ethical judgments (pp. 44-69). New York: Routledge.

Van Lange, P. A. M., \& Joireman, J. A. (2010). Social and temporal orientations in social dilemmas. In R. M. Kramer, A. E. Trenbrunsel, \& M. H. Bazerman (Eds.), Social decision making: Social dilemmas, social values, and ethical judgments (pp. 71-94). New York: Routledge.

Zizzo, D. J., \& Oswald, A. (2001). Are people willing to pay to reduce others' incomes? Annals of Economics and Statistics, 63-64, 39-65. 